\title{
SINKRONISASI KOMPETENSI MAHASISWA DENGAN KOMPETENSI TUNTUTAN SEKOLAH DALAM PELAKSANAAN PPL DI SEKOLAH DASAR DI DAERAH PERBATASAN
}

\author{
Vlorensius, Muhsinah Annisa \\ FKIP Universitas Borneo Tarakan
}

\begin{abstract}
ABSTRAK
Tujuan penelitian ini adalah untuk menganalisis kesinkronan kompetensi mahasiswa FKIP Universitas Borneo Tarakan dengan kompetensi tuntutan sekolah dalam pelaksanaan PPL di sekolah dasar di daerah perbatasan. Pendekatan metode penelitian ini adalah deskriptif kuantitatif, sedangkan jenis penelitian ini adalah penelitian survey. Teknik pengambilan data pada penelitian ini adalah dengan wawancara, dokumentasi dan penyebaran angket pada guru dan kepala sekolah di sekolah dasar tempat pelaksanaan PPL yang berjumlah 15 sekolah. Hasil penelitian ini secara umum yaitu kesesuaian kompetensi kebutuhan sekolah dan kompetensi mahasiswa adalah sesuai, hal ini didasari pada hasil angket tentang pelaksanaan PPL secara umum $34.3 \%$ (sangat setuju) dan $61.3 \%$ (setuju), pada kompetensi pedagogik $13.3 \%$ (sangat baik) dan $56.4 \%$ (baik), pada kompetensi sosial $67.3 \%$ (sangat baik) dan $23.6 \%$ (baik), pada kompetensi profesional $30.5 \%$ (sangat baik) dan 54.5\% (baik), dan kompetensi keahlian 12.7\% (sangat baik) dan $50.5 \%$ (baik).
\end{abstract}

Kata kunci : Kompetensi mahasiswa, Kompetensi tuntutan sekolah, Daerah perbatasan, PPL

\section{PENDAHULUAN}

Universitas Borneo Tarakan
(UBT) merupakan satu-satunya
universitas negeri di wilayah Kalimantan
bagian utara, yang terletak di kota
Tarakan.UBT memiliki Fakultas

Keguruan dan Ilmu Pengetahuan (FKIP) yang diharapkan menghasilkan lulusan calon guru profesional. Hal ini sesuai dengan Undang-undang Republik Indonesia Nomor 20 Tahun 2003 tentang sistem Pendidikan Nasional, pasal 42 bahwa setiap pendidik dituntut untuk memiliki kualifikasi dan sertifikasi yang dipersyaratkan sesuai dengan jenjang kewenangan mengajar, sehat jasmani dan rohani, serta memiliki kemampuan untuk mewujudkan tujuan pendidikan nasional. Dengan demikian, setiap pendidik harus memiliki kompetensi untuk menjadi guru profesional sebagaimana yang telah dipersyaratkan dalam Undang-Undang Guru dan Dosen maupun Standar Nasional Pendidikan (Peraturan Pemerintah
Republik Indonesia Nomor: 19 Tahun 2005),yaitu kompetensi pedagogik, kompetensi kepribadian, kompetensi professional dan kompetensi sosial.Empat kompetensi tersebut diperoleh mahasiswa selama menempuh jalur pendidikan di perguruan tinggi, oleh karena itu, Universitas Borneo Tarakan sebagai penghasil calon guru, telah menyelenggarakan Praktik Pengalaman Lapangan (PPL) dalam menyiapkan mahasiswa menjadi calon guru yang profesional.

Pengalaman Praktik Lapangan (PPL) merupakan salah satu kulminasi atau muara program yang memberikan kesempatan kepada mahasiswa untuk memantapkan kompetensi pedagogik, kepribadian, profesional dan sosial dalam rangka memperbaiki atau meningkatkan mutu pembelajaran di kelas (Tim PPL, 2010).Mengelola pembelajaran di kelas merupakan salah satu pekerjaan guru profesional yang berorientasi pada 
kebutuhan peserta didik.Sebagai wujud dari penguasaan kompetensi itu, setiap tindakan guru dalam mengelola pembelajaran merupakan tindakan pengambilan keputusan yang dapat dipertanggungjawabkan secara keilmuan, profesi dan moral.Kompetensi yang dimiliki oleh mahasiswa dalam pelaksanaan PPL di sekolah diperoleh melalui pendidikan dan pelatihan yang sistematik dan terprogram oleh institusi yang berkompeten.

Pada pelaksanaan Praktik

Pengalaman Lapangan (PPL) melalui banyak interaksi yang bermakna, interaksi antar mahasiswa PPL, mahasiswa dengan siswa, mahasiswa dengan guru pamong, mahasiswa dengan guru pengajar di sekolah dan interaksi mahasiswa dengan kepala sekolah beserta staf tata usaha. Oleh karena itu, pelaksanaan PPL harus memberikan kesempatan agar terjadi interaksi-interaksi tersebut yang akan menumbuhkembangkan kompetensi yang perlu dimiliki oleh seorang guru.Semua pihak yang terlibat dalam pelaksanaan PPL harus mempunyai kesamaan persepsi dalam kompetensi apa yang dibutuhkan oleh pihak sekolah sebagai pengguna lulusan. Kesamaan persepsi sangat penting demi keberhasilan pelaksanaan PPL. Oleh karena itu perlu adanya kesamaan persepsi mengenai kompetensi mahasiswa PPL yang sesuai dengan harapan pengguna lulusan (sekolah) dan stake holder. Berdasarkan uraian tersebut, perlu adanya penelitian mengenai singkronisasi kompetensi mahasiswa dengan kompetensi tuntutan pihak sekolah selaku pengguna lulusan FKIP Universita Borneo Tarakan.

\section{METODE PENELITIAN Jenis Penelitian}

Pendekatan pada penelitian ini adalah deskriptif kuantitatif, sedangkan jenis penelitian ini adalah penelitian survey.Teknik pengambilan data pada penelitian ini adalah dengan wawancara, dokumentasi dan penyebaran angket pada sekolah dasar tempat pelaksanaan PPL yang berjumlah 15 sekolah.

\section{Subyek dan Waktu Penelitian}

Subyek pada penelitian ini adalah guru pamong, guru sekolah, karyawan dan kepala sekolah tempat pelaksanaan PPL. Populasi yang diambil dalam penelitian ini yaitu sekolah dasar di kota Tarakan. Penentuan sampel dilakukan secara acak dengan pengelompokan sekolah dasar berkategori bagus, sedang dan rendah. Penelitian dilakukan dari bulan MeiOktober 2013.

\section{Data dan Sumber Data}

Data utama penelitian dikumpulkan dengan menyebarkan angket dan wawancara kepada guru pamong, guru, karyawan sekolah dan kepala sekolah di sekolah perbatasan yang berjumlah 15 sekolah.

\section{Instrumen Penelitian}

Instrumen penelitian ini adalah angket.Angket pada penelitian ini memiliki empat indikator kompetensi guru yang wajib dimiliki oleh guru profesional dan juga hal-hal yang terkait dengan kebutuhan sekolah akan calon guru.

\section{Teknik Analisis Data}

Data yang terkumpul kemudian dianalisis baik secara kuantitatif maupun kualitatif. Pengolahan data kuantitatif dilakukan dengan teknik statistik deskriptif Pengolahan data kualitatif dilakukan untuk memaparkan kompetensi yang dibutuhkan oleh pihak sekolah selaku pengguna lulusan, dari paparan data tersebut bias ditarik kesimpulan mengenai kompetensi mahasiswa yang dibutuhkan oleh pihak sekolah atau stakeholder. 
Tabel 4.1 Skor Penilaian Pernyataan Pelaksanaan PPL

\begin{tabular}{|l|l|c|}
\hline NO & \multicolumn{1}{|c|}{ Pernyataan } & Skor Penilaian \\
\hline $\mathbf{1}$ & Sangat setuju/Sangat Baik & 5 \\
\hline $\mathbf{2}$ & Setuju/Baik & 4 \\
\hline $\mathbf{3}$ & Ragu-ragu/Cukup Baik & 3 \\
\hline $\mathbf{4}$ & Tidak Setuju/Tidak Baik & 2 \\
\hline $\mathbf{5}$ & $\begin{array}{l}\text { Sangat Tidak } \\
\text { Setuju/Sangat Tidak Baik }\end{array}$ & 1 \\
\hline
\end{tabular}

Hasil penskoran dideskripsikan sebagai berikut.

$1,0 \leq \mathrm{M} M<1,99$ : berarti "sangat tidak baik" atau "sangat tidak setuju"

$2,0 \leq \mathrm{M} \mathrm{M}<2,99$ : berarti "tidak baik" atau "tidak setuju"

$3,0 \leq \mathrm{M} \mathrm{M}<3,8$ : berarti "cukup baik" atau "ragu-ragu"

$3,8 \leq \mathrm{M} \mathrm{M}<4,5$ : berarti " baik" atau "setuju"

$4,5 \leq M M \leq 5,0$ : berarti "sangat baik" atau "sangat setuju"

Keterangan:

$X=$ Skor Pernyataan $\quad$ (Ratumanan \&Lourens ; 2006: 19)

\section{HASIL DAN PEMBAHASAN}

Penelitian ini dilakukan dari bulan

Mei - Oktober 2013. penelitian ini dilakukan pada 15 sekolah, yaitu SDN Utama 01, SDN Utama 02, SDN 009, SDN 029, SDN 034, SDN 024, SDN 018, SDN 006, SDN 013, SDN 015, SDN 016, SDN 031, SDN 045, SDN 012, SDN 030 Kota Tarakan. Subjek penelitian ini adalah kepala sekolah, guru dan karyawan sekolah tersebut.Data penelitian ini berupa angket tertutup untuk menjaring data tentang pendapat pihak sekolah mengenai pelaksanaan PPL agar dapat mengetahui kesesuaian kebutuhan sekolah dengan kompetensi yang dihasilkan oleh pihak PGSD.berdasarkan sebaran angket didapat sebagai berikut.

\section{Pelaksanaan Secara Umum}

Data pelaksanaan PPL secara umum disajikan pada Tabel 5.1 sebagai berikut.

Tabel 5.1 Angket Pelaksanaan PPL Secara Umum

\begin{tabular}{|c|l|c|c|c|c|c|}
\hline \multirow{2}{*}{ No. } & \multicolumn{1}{|c|}{ Pernyataan } & \multicolumn{5}{|c|}{ Skor (\%) } \\
\cline { 3 - 7 } & \multicolumn{1}{|c|}{5} & 4 & 3 & 2 & 1 \\
\hline 1 & $\begin{array}{l}\text { Sebagai calon guru, mahasiswa wajib melaksanakan } \\
\text { PPL di sekolah }\end{array}$ & 72.7 & 27.3 & 0.0 & 0.0 & 0.0 \\
\hline 2 & Sekolah Anda sebagai tempat pelaksanaan PPL & 40.0 & 60.0 & 0.0 & 0.0 & 0.0 \\
\hline 3 & $\begin{array}{l}\text { PPL dilaksanakan setiap semester (ganjil dan } \\
\text { genap) }\end{array}$ & 20.0 & 80.0 & 0.0 & 0.0 & 0.0 \\
\hline 4 & $\begin{array}{l}\text { Pelaksanaan PPL yang telah dilaksanakan di } \\
\text { sekolah Anda }\end{array}$ & 20.0 & 65.5 & 14.5 & 0.0 & 0.0 \\
\hline 5 & $\begin{array}{l}\text { Waktu pelaksanaan PPL di sekolah Anda selama } \\
\text { satu semester }\end{array}$ & 21.8 & 74.5 & 3.6 & 0.0 & 0.0 \\
\hline 6 & $\begin{array}{l}\text { Manfaat pelaksanaan PPL oleh mahasiswa bagi } \\
\text { sekolah }\end{array}$ & 40.0 & 49.1 & 10.9 & 0.0 & 0.0 \\
\hline 7 & $\begin{array}{l}\text { Mahasiswa dalam pelaksanaan PPL wajib diberikan } \\
\text { tugas tambahan oleh sekolah }\end{array}$ & 25.5 & 72.7 & 1.8 & 0.0 & 0.0 \\
\hline \multicolumn{1}{|c|}{ Rata-rata } & 34.3 & 61.3 & 4.4 & 0.0 & 0.0 \\
\hline
\end{tabular}


Berdasarkan penyataan pada Tabel 5.1, Pada pelaksanaan PPL secara umum, $34.3 \%$ sangat setuju, dan $61.3 \%$ setuju dan $4.4 \%$ ragu-ragutentang pelaksanaan PPL pada sekolah mereka dan dilakukan selama 1 semester, baik berada di semester ganjil atau semester genap, pihak sekolah juga bersedia sekolah mereka dijadikan sebagai tempat pelaksanan PPL.

Secara umum pihak sekolah merasakan bahwa pelaksanaan PPL di sekolah mereka terlaksana dengan baik dan bermanfaat.berdasarkan wawancara dengan pihak sekolah, pelaksanaan PPL berjalan dengan baik, mahasiswa menaati peraturan yang dibuat sekolah, baik dalam hal kehadiran di sekolah maupun dalam hal pengajaran dan tugas-tugas yang diberikan oleh pihak sekolah, sehingga dengan adanya pelaksanaan PPL di sekolah, sekolah merasakan manfaat dengan pelaksanaan PPL, karena guru dan staf juga dapat terbantukan baik dalam mengajar dan tugas administrasi.

\section{Kompetensi Pedagogik}

berikut.

Data pelaksanaan PPL ditinjau dari aspek pedagogik disajikan pada tabel 5.2

Tabel 5.2 Angket Pelaksanaan PPL pada Kompetensi Pedagogik

\begin{tabular}{|c|l|c|c|c|c|c|}
\hline \multirow{2}{*}{ No. } & \multicolumn{1}{|c|}{ Pernyataan } & \multicolumn{5}{c|}{ Skor (\%) } \\
\cline { 3 - 8 } 1 & $\begin{array}{l}\text { Pelaksanaan konseling siswa oleh mahasiswa } \\
\text { PPL }\end{array}$ & 3.6 & 63.6 & 32.7 & 0.0 & 0.0 \\
\hline 2 & $\begin{array}{l}\text { Mahasiswa memanfaatkan TIK dalam proses } \\
\text { pembelajaran }\end{array}$ & 16.4 & 56.4 & 27.3 & 0.0 & 0.0 \\
\hline 3 & Kemampuan mahasiswa dalam mengajar & 10.9 & 58.2 & 30.9 & 0.0 & 0.0 \\
\hline 4 & $\begin{array}{l}\text { Mahasiswa melaksanakan tugas kookurikuler di } \\
\text { sekolah }\end{array}$ & 7.3 & 56.4 & 34.5 & 1.8 & 0.0 \\
\hline 5 & $\begin{array}{l}\text { Mahasiswa melaksanakan tugas ekstrakurikuler } \\
\text { di sekolah }\end{array}$ & 9.09 & 40.0 & 49.1 & 1.8 & 0.0 \\
\hline 6 & $\begin{array}{l}\text { Pemberian tugas tambahan sebagai pembina } \\
\text { upacara oleh sekolah kepada mahasiswa PPL }\end{array}$ & 32.7 & 63.6 & 3.6 & 0 & 0.0 \\
\hline \multicolumn{1}{|c|}{ Rata-rata } & 13.3 & 56.4 & 29.7 & 0.6 & 0.0 \\
\hline
\end{tabular}

Berdasarkan Tabel 5.2, secara umum sebanyak $13.3 \%$ sangat baik, $56.4 \%$ baik, 29.7 cukup baik dan $0.6 \%$ tidak baikyang meliputi pelaksanaan konseling oleh mahasiswa, pemanfaatan TIK dalam pembelajaran, kemampuan mengajar mahasiswa, serta pelaksanaan tugas kookuler dan ekstrakurikuler. Mahasiswa melakukan konseling pada siswa yang memiliki permasalahn dan terlihat kurang ceria selama pembelajaran dengan cara melakukan pendekatan secara personal. sebagian besar mahasiswa mampu mengajar dengan baik, hal ini disebabkan saat di perkuliahan, mahasiswa berlatih dalam mengajar dengan adanya mata kuliah mickroteaching 5 Mata Pelajaran, yaitu IPA,IPS, Bahasa Indonesia, Matematika dan Pkn. sebelum menempuh mata kuliah mickroteaching, mahasiswa dibekali ilmu yang berkaitan dengan cara mengajar, profesi guru dan psikologi pendidikan. 


\section{Kompetensi Keahlian}

Data pelaksanaan PPL ditinjau dari aspek pedagogik disajikan pada tabel 5.3 berikut.

Tabel 5.3 Angket Pelaksanaan PPL pada Kompetensi Keahlian

\begin{tabular}{|c|l|c|c|c|c|c|}
\hline \multirow{2}{*}{ No } & \multicolumn{1}{|c|}{ Pernyataan } & \multicolumn{5}{c|}{ Skor (\%) } \\
\cline { 3 - 7 } & \multicolumn{1}{|c|}{5} & 4 & 3 & 2 & 1 \\
\hline 1 & $\begin{array}{l}\text { Tanggung jawab mahasiswa terhadap tugas } \\
\text { mengajar yang diberikan oleh sekolah Anda }\end{array}$ & 20.0 & 65.5 & 12.7 & 1.8 & 0.0 \\
\hline 2 & $\begin{array}{l}\text { Kedisiplinan mahasiswa selama pelaksanaan PPL di } \\
\text { sekolah Anda }\end{array}$ & 18.2 & 54.5 & 21.8 & 5.5 & 0.0 \\
\hline 3 & $\begin{array}{l}\text { Busana yang dikenakan sesuai dengan } \\
\text { profesionalisme seorang guru }\end{array}$ & 16.4 & 60.0 & 23.6 & 0.0 & 0.0 \\
\hline 4 & $\begin{array}{l}\text { Mahasiswa mampu menjadi teladan bagi peserta } \\
\text { didik }\end{array}$ & 21.8 & 54.5 & 23.6 & 0.0 & 0.0 \\
\hline 5 & $\begin{array}{l}\text { Pemberian jam mengajar yang ideal per minggu } \\
\text { kepada mahasiswa PPL di sekolah Anda }\end{array}$ & 67.3 & 23.6 & 5.5 & 3.6 & 0.0 \\
\hline \multicolumn{1}{|c|}{ Rata-rata } & 19.1 & 58.6 & 20.5 & 1.8 & 0.0 \\
\hline
\end{tabular}

Berdasarkan Tabel 5.3 ditinjau dari aspek kompetensi keahlian, secara umum $67.3 \%$ sangat baik, $23.6 \%$ baik, $5.5 \%$ cukup baik, $3.6 \%$ kurang baik. Sebagian besar mahasiswa melaksanakan tugas mengajar yang diberikan sekolah, walaupun masih beberapa mahasiswa yang tidal melaksanakan tanggung jawab dengan baik, hal ini disebabkan karakteristik mahasiswa tersebut dan watu mengajar yang bersamaan dengan waktu perkuliahan mahasiswa, karena sebagian mahasiswa masih memprogram mata kuliah bersamaan dengan pelaksanaan PPL. Dalam hal kedisiplinan mahasiswa, masih ada mahasiswa yang terlambat datang di sekolah serta kurang patuh pada aturan di sekolah.Dalam hal berbusana, secara umum baik, karena mahasiswa memiliki kewajiban menggunakan pakaian yang sesuai dengan profesi mereka sebagai guru, seperti menggunakan kemeja dan celana kain bagi laki-laki, serta rok kain dan kemeja bagi mahasiswi.Pembiasaan mahasiswa tersebut sudah tercermin sejak dalam perkuliahan, karena mahasiswa PGSD diwajibkan menggunakan pakaian seragam, yaitu atasan putih dan celana kain hitam/rok hitam.Cara berpakaiandapat memberikan contoh yang baik bagi peserta didik agar dapat menggunakan busana yang sesuai dengan budaya timur yang selama ini kita anut.

Dalam hal pemberian jam mengajar $67.3 \%$ memilih 8-12 Jam /minggu, $23.6 \%$ memilih 12-16 Jam/Minggu, $5.5 \%$ memilih 17-20 jam/minggu dan 3.6\% memilih 20-24 $\mathrm{Jam} / \mathrm{minggu}$. pemberian jam mengajar dapat membuat mahasiswa memiliki rasa tanggung jawab terhadap kewajiban yang diembannya, mahasiswa dapat belajar bagaimana menjadi guru yang professional, terutama dalam hal mengajar, penguasaan kelas,dan lain lain, yang mana hal itu harus didapat melalui pengalaman nyata, bukan hanya sekedar teori. teori yang didapat dalam perkuliahan hendaknya diaplikasikan dalam dunia nyata (pembelajaran di sekolah), karena hal itulah yang akan membuat mahasiswa dapat lebih banyak belajar dari pengalaman langsung. 


\section{Kompetensi Sosial}

Data pelaksanaan PPL ditinjau dari aspek pedagogik disajikan pada tabel 5.4 berikut.

Tabel 5.4 Angket Pelaksanaan PPL pada Kompetensi Sosial

\begin{tabular}{|c|l|c|c|c|c|c|}
\hline \multirow{2}{*}{ No. } & \multicolumn{7}{|c|}{ Pernyataan } & \multicolumn{5}{c|}{ Skor (\%) } \\
\cline { 3 - 7 } & & 5 & 4 & 3 & 2 & 1 \\
\hline 1 & $\begin{array}{l}\text { Hubungan mahasiswa dengan Kepala } \\
\text { sekolah/Wakil }\end{array}$ & 29.1 & 56.4 & 14.5 & 0.0 & 0.0 \\
\hline 2 & Hubungan mahasiswa dengan Guru & 32.7 & 50.9 & 16.4 & 0.0 & 0.0 \\
\hline 3 & Hubungan mahasiswa dengan karyawan sekolah & 25.5 & 56.4 & 18.2 & 0.0 & 0.0 \\
\hline 4 & Hubungan mahasiswa dengan siswa & 34.5 & 54.5 & 10.9 & 0.0 & 0.0 \\
\hline & Rata-rata & 30.5 & 54.5 & 15.0 & 0.0 & 0.0 \\
\hline
\end{tabular}

Berdasarkan Tabel 5.3 ditinjau dari aspek kompetensi sosial, secara umum $30.5 \%$ sangat baik, $54.5 \%$ baik,
$15 \%$ cukup baik meliputi hubungan mahasiswa dengan kepala sekolah/wakil, guru, karyawan dan peserta didik.

\section{Kompetensi Profesional}

Data pelaksanaan PPL ditinjau dari aspek pedagogik disajikan pada tabel 5.5 berikut.

Tabel 5.5 Angket Pelaksanaan PPL pada Kompetensi Profesional

\begin{tabular}{|c|l|r|r|r|c|c|}
\hline \multirow{2}{*}{ No. } & \multicolumn{1}{|c|}{ Pernyataan } & \multicolumn{5}{c|}{ Skor (\%) } \\
\cline { 3 - 8 } 1 & \multicolumn{1}{|c|}{$\begin{array}{l}\text { Penguasaan konsep/materi mata pelajaran yang } \\
\text { dimiliki mahasiswa }\end{array}$} & 5.5 & 65.5 & 27.3 & 1.8 & 0.0 \\
\hline 2 & Mahasiswa membuat silabus pembelajaran & 16.4 & 45.5 & 32.7 & 5.5 & 0.0 \\
\hline 3 & $\begin{array}{l}\text { Mahasiswa membuat rencana pelaksanaan } \\
\text { pembelajaran }\end{array}$ & 20.0 & 45.5 & 30.9 & 3.6 & 0.0 \\
\hline 4 & $\begin{array}{l}\text { Mahasiswa membuat media pembelajaran yang } \\
\text { bervariatif }\end{array}$ & 9.1 & 45.5 & 36.4 & 9.1 & 0.0 \\
\hline & \multicolumn{1}{|l}{ Rata - rata } & 12.7 & 50.5 & 31.8 & 5.0 & 0.0 \\
\hline
\end{tabular}


Berdasarkan Tabel 5.5 ditinjau dari aspek kompetensi professional, $12.7 \%$ sangat baik, $50.5 \%$ baik, 3.18 cukup baik dan $5 \%$ tidak baik. meliputipenguasaan konsep mata pelajaran, membuat silabus, RPP dan media. Dalam perkuliahan, mahasiswa dibekali konsep dasar keilmuan yang diajarkan di sekolah dasar, selain itu mahasiswa dibekali keterampilan dalam membuat RPP dan silabus yang sesuai dengan kurikulum yang berlaku.

\section{KESIMPULAN DAN SARAN Kesimpulan}

Kesimpulan penelitian ini yaitu kesesuaian kompetensi kebutuhan sekolah dan kompetensi mahasiswa adalah sesuai, hal ini didasari pada hasil angket tentang pelaksanaan PPL secara umum 34.3\% (sangat setuju) dan $61.3 \%$ (setuju), pada kompetensi pedagogik 13.3\% (sangat baik) dan $56.4 \%$ (baik), pada kompetensi sosial $67.3 \%$ (sangat baik) dan $23.6 \%$ (baik), pada kompetensi profesional $30.5 \%$ (sangat baik) dan $54.5 \%$ (baik), dan kompetensi keahlian $12.7 \%$ (sangat baik) dan $50.5 \%$ (baik).

\section{Saran}

Berdasarkan penelitian yang telah dilakukan, peneliti memberikan saransaran sebagai berikut:

1. Hendaknya mahasiswa yang memprogram mata kuliah PPL, pengambilan jumlah SKS dibatasi agar mahasiswa dapat lebih fokus dalam pelaksanaan PPL di sekolah dasar.

2. Hendaknya mahasiswa PPL lebih sering dikunjungi dan didampingi oleh Dosen Pembimbing, supaya Mahasiswa lebih merasa diperhatikan dan mudah berkoordinasi dengan pihak sekolah (Guru Pamong)

\section{DAFTAR PUSTAKA}

Departemen Pendidikan Nasional. 2007. Permendiknas No.16 Tahun
2007Standar Kualifikasi Akademik dan Kompetensi Guru.

Republik Indonesia, 2005.Undang-undang Nomor 14 Tahun 2005 Tentang Guru dan Dosen. Jakarta

Undang-undang Republik Indonesia Nomor 20 Tahun 2003 tentang sistem Pendidikan Nasional

Peraturan Pemerintah Republik Indonesia Nomor: 19 Tahun 2005

Peraturan Pemerintah No.47 Tahun 1981 www.tarakankota.go.id diakses tanggal 10 Maret 2013

Tim PPL, 2010. Petunjuk Teknis Pelaksanaan PPL: Tidak diterbitkan. 